\title{
Bernhard Milt
}

\section{November 1896 bis 18. März 1956}

Am 18. März 1956 starb plötzlich an einem Herzinfarkt Prof. Dr. Bernhard MrLt, Extraordinarius für Geschichte der Medizin und Biologie an der Universität Zürich. Die Schweizerische Gesellschaft für Geschichte der Medizin und der Naturwissenschaften erleidet durch den Hinschied ihres langjährigen Mitgliedes Prof. Dr. med. Bernhard Milt einen außerordentlich schweren Verlust. Ein liebenswerter Mensch, ein Mann von reichen geistigen Gaben und ein Gelehrter von Rang ist mit ihm dahingegangen. Unserer Gesellschaft leistete er als Vorstandsmitglied wertvollste Dienste. Die Medizingeschichte verdankt Bernhard Milt eine große Zahl origineller Arbeiten, deren Bedeutung an anderer Stelle gewürdigt werden soll. Seine Liebe galt besonders der Medizingeschichte des Bodenseekreises mit Einschluß St.Gallens (wo Milt seine Jugend verbrachte), Zürichs, welches ihm zur zweiten Heimat wurde, und der Schweiz im allgemeinen.

Die Hauptstationen seiner wissenschaftlichen Tätigkeit bilden die Medizingeschichte des Mittelalters im Bodenseegebiet und in Zürich, Studien über Vadian, Paracelsus, Conrad und Johannes Gessner, Franz Anton Mesmer.

Die medizinhistorischen Arbeiten Bernhard Milts tragen in allem den Stempel seiner ausgeprägten Persönlichkeit. Sie verraten den philosophischen, religiös interessierten, humanistisch gebildeten Geist. Es war Milts bewundernswerte, durch große Selbstdisziplin entwickelte Fähigkeit «in des Ursprungs Tiefe» zu dringen und, von eingehenden Quellenstudien ausgehend, den Kern der Dinge herauszuarbeiten und das oft sehr mühsam Errungene in den großen Zusammenhang einer Epoche einzuordnen, ohne je Maß und Proportion in der Wertung der Einzelergebnisse zu verlieren.

Milts Arbeiten waren immer erhellend, weil er das Wesentliche nicht nur zu erfassen, sondern auch in anschaulicher Form darzustellen wußte. Den Lesern des Gesnerus werden seine Aufsätze ebenso wie seine ausführlichen Buchbesprechungen in guter Erinnerung bleiben; denn auch diese bedeuteten nicht nur sachliche Kritik, sondern Bereicherung.

Unsere Gesellschaft verliert in B. Milt eines ihrer aktivsten Mitglieder. Ja man darf sagen, daß Milt an den Tagungen unserer Gesellschaft immer mehr zum Mittelpunkt wurde. Seine Diskussionsbemerkungen legten von seinem beziehungsreichen Wissen, seinem kritischen Urteil und seiner Fähigkeit anschaulicher Darstellung beredtes Zeugnis ab.

Im Jahre 1948 habilitierte sich Milt an der Zürcher Universität mit der bedeutenden Arbeit über Franz Anton Mesmer und seine Beziehungen zur Schweiz. Auf Anfang 1951 erfolgte seine Wahl zum außerordentlichen Professor für Geschichte der Medizin und Biologie und zum Direktor des Medizingeschichtlichen Institutes 
der Universität Zürich. Die nun stark vermehrten Unterrichtsanforderungen, die Leitung des Institutes und die Ausgestaltung der Sammlung zwangen ihn zur Aufgabe seiner internistischen Privatpraxis.

Die «Pura-Tagungen», im Kreise von Altmeister Henri Sigerist, deren Organisation Milt übertragen worden waren, gelangten unter seiner diskreten Führung zu schönster Blüte. Alle, die mit ihm schöne Frühlingstage in Pura verbracht haben, sind von seinem allzufrühen Hinschied aufs schmerzlichste berührt.

Milt genoß auch im Ausland steigendes Ansehen, nicht nur im deutschen Sprachgebiet, sondern insbesondere auch in England und in den USA. Man schätzte an ihm seine große Zuverlässigkeit und sein reiches und stets präsentes fachliches Wissen. Sein bescheidenes, konziliantes Wesen und seine im verborgenen temperamentvolle, dem Humor zugängliche Persönlichkeit trugen ihm überall Sympathien ein.

Die Schweizerische Gesellschaft für Geschichte der Medizin und der Naturwissenschaften, die Freunde des Pura-Kreises, die Redaktion des Gesnerus und darüber hinaus viele Kollegen des In- und Auslandes betrauern den Hinschied Bernhard Milts aufs tiefste.

Sie werden ihm stets ein ehrendes Andenken bewahren.

Hans Fischer 